Biosight 2021; 02(01): 24-30

\title{
Prevalence of Various Sign and Symptoms of Diabetic Peripheral Neuropathy
}

\author{
Kahkshan Asif, Qurat ul ain* \\ Department of Physiology, University of Karachi, Karachi, Pakistan, 75270
}

Received: March 16, 2021 Accepted: June 06, 2021

\begin{abstract}
BACKGROUND: Diabetes mellitus (DM) is a chronic metabolic syndrome marked by hyperglycemia due to absolute or relative deficiency of insulin hormone. Diabetic neuropathy is a complication of both type 1 and type 2 diabetes. Although pain is one of the most dominant symptoms of diabetic neuropathy, its pathophysiological mechanisms yet unknown. Toxic effects of high glucose levels play an important role in the development of this complication.

METHODOLOGY: Data was collected through the questionnaire regarding Clinical findings, medical records, weight, age, family history, different habits, and psychogenic behavior. All the patients with the mentioned diseases are included in this study, excluding the mentally ill patients and the pregnant women.

RESULT: The result of the present study showed that diabetic neuropathy is the most common complication of diabetes mellitus. It has been observed that most of the patients due to lack of awareness are suspected to the elevated or extreme blood sugar level which leads to neuropathy. Due to the Diabetic Peripheral Neuropathy (DPN) most of the patients suffering from foot problems, foot ulcers and then amputations. Lack of awareness, lack of health management, obesity, blood pressure changes, less care plays a key role in increasing the chances of diabetic neuropathy. COCLUSION: Diabetic neuropathy had very bad influence on a person's health and daily activities. The Patient education programs need to emphasize on large scale. The ultimate aim of this study is the foot care education for people with the diabetes and to prevent foot ulcers and amputation.
\end{abstract}

Keywords: Diabetes, Diabetic neuropathy, Hyperglycemia, Diabetic Peripheral Neuropathy, Foot infection, DPN.

Correspondence: Qurat ul ain, Department of Physiology, University of Karachi, Pakistan. Phone: +92-345-53119232 Email: qrtlnain@yahoo.com

\section{INTRODUCTION}

Peripheral neuropathy is a very frequent complication of the diabetes [8]. The most frequent type of peripheral neuropathy in diabetes mellitus is the Distal Sensory Polyneuropathy (DSP), identifies by uniformly, or constant, toe and distal foot numbness, paresthesia (feeling of tingling or pricking), with or without neuropathic pain. The frequency of distal polyneuropathy increases with the extended lead time of diabetes mellitus. The periodicity of the neuropathy was increased in the patients with the less care or poor control, reemphasizing the importance of diabetic control in the prevention of the obstacles of diabetes [10].

Diabetic peripheral neuropathy (DPN) associated with very bad or poor quality of life. It is identified by pain, paresthesia and the sensory loss. Problems of diabetes mellitus include a variation of clinical attributes, predominantly connected to the participation of the arterial wall both of the large vessels i.e., macroangiopathy and the small vessels i.e., microangiopathy, and peripheral nervous system i.e., neuropathy [9]. Hyperglycemia, accelerate the metabolic deformities, i.e. non-enzymatic glycosylation of the proteins and polyol cycle activity; besides, it can badly affect the regulation of some of the hormones, specifically Growth hormones and sex steroids, and normal properties of clotting of blood. Diabetic neuropathy has a great variation of clinical demonstration, at somatic, autonomic and the central measures and can highly alter the quality and anticipation of life [11]. Even though, main cause of death in the diabetic subjects is the large vessel disease or the macro angiopathy, which alike non-diabetic atherosclerosis in regards to the main histological, pathological and the clinical demonstration but has higher universality and bad impact on life. Hypertension is related with worse nerve condition in type 1 
diabetes mellitus. Hypertension was found in $40-70$ patients of type 1 diabetes [12]. A distinct cardiomyopathy (it is a disease of heart muscles. As it causes the heart muscle to become enlarged and rigid) has also been found in diabetics. Symptoms of muscle weakness tend to develop later in the disease course.

Advancement in ANS (Autonomic nervous system) balance may be difficult in the reduction of cardiovascular system and early death. Signs of autonomic ailment, including relaxed state HR (heart rate), BP (blood pressure) responses to the standing, and time period and frequency measures of the HRV (heart rate variability) in reaction to deep breathing, standing and Valsalva maneuver, should obtain from every single patient with diabetes to find early diagnosis and interposition [13]. Painful signs like burning sensation, tingling (paresthesia), shooting (like electric powered shock) or lancing (stabbing) found in around a third of the sufferings with DPN and around $20 \%$ of all the patients with diabetes [7]. The signs and symptoms are usually worse in the night time and disturb sleep pattern. Together with the excessive and painful signs during the day, this repeatedly leads to a reduction in the individual's capability to perform routine tasks and routine work [1]. Persistent discomfort is found despite polypharmacy (use of multiple medication), leads to the obstructions in daily activities and less satisfaction with the treatments and regular checkups. DPN can be extremely grieving and might occur with anxiety together with sadden condition and stress. However, symptoms are not a reliable measure of the severity of the damage of the nerves.

The diabetic neuropathies might be heterogeneous, affecting different areas of the nervous system. They may be central or may be diffuse. Among the neuropathies the most common are the chronic sensorimotor distal symmetric polyneuropathy (DPN) and the autonomic neuropathies [6].

Early identification and control by managing neuropathy in patients with diabetes is very important for multiple causes [5].

1) The Non diabetic neuropathies may also found in patients with diabetes.

2) Various treatment options are there for the patients with signs and symptoms of diabetic neuropathy.

3) Up to $50 \%$ of the patients are asymptomatic, and patients are at high risk of wound or injury to their feet. As greater than $80 \%$ of the amputations follow a foot ulcer or severe injury, early diagnosis of at great risk individuals, the purpose of the education/awareness, and foot care can take to lack occurrence of ulceration and accordingly the amputations.

4) Autonomic neuropathy might destroy all the systems in the body.

5) Autonomic neuropathy leads to considerable disease and elevated mortality, mainly if cardiovascular autonomic neuropathy (CAN) is found [2]. In the natural history of DPN, usually those who suffer from disease are asymptomatic.

There are also some evidences that focal inflammatory, including vasiculitis, lesions may also involve in the proximal lower limb neuropathies. Finally, it may lead to the chronic inflammatory demyelinating polyneuropathy. For the identification of possible treatments, it is much necessary that cases and reports should be marked as to type correctly [12].

Both neuropathy and the vasculopathy are very strong, independent risk factors for the growth of foot ulcers in diabetics [8]. Diabetic peripheral neuropathy (DPN) affects more up to fifty percent of older type 2 diabetic patients. Whereas few patients face extreme signs, other patients with a more prominent neuropathy may be asymptomatic or with very less symptoms. Diagnosis should be according to the careful inspection of the lower limbs. In Medications, there may be usually the tricyclic drugs or the anticonvulsant agents may be required. Those who suffered with the peripheral neuropathy probably at the risk of foot ulceration and must get deterrent education and foot care. In former times, a lack of awareness and unproductive ways of management of the diabetic peripheral neuropathy (DPN) causes much unnecessary ailment and the considerable health care costs. Least wise half of all the foot ulcers, the most advanced stage 
of neuropathy, should be cure by suitable management and care and by the patient awareness [1].

The aim of the study is to find out the prevalence of diabetes and painful/irritating diabetic peripheral neuropathy (PDPN) in a population-based sample and to evaluate its extremity and impact.

\section{METHODLOGY}

Acquisition of Data: The present study was organized in the urban areas of Karachi, Pakistan. Different Hospitals of different areas have been surveyed. All the patients of either sex of every age were included in this study. Consent form was filled prior to collection of any data and questionnaire form filling. The sample size of the study was 50, all the subjects that were participated in this study have DPN with varying degree of signs and symptoms that were further subdivide to into groups on the basis of gender Group I male $n=33$ and Group II female $n=17$. Every patient was explained about the criteria of the study and after taking their consent, detailed history was collected by the interviewer and physical examination was performed. No such blood tests were performed. A questionnaire was designed and validated by research supervisor and subject expert to record the demographic profile and determine the risk factors of diabetes and the severe diabetic neuropathy, psychogenic conditions, family history, hypertension, drug uses, certain lifestyle and complications. Information about reports was recorded from the medical reports available in each patient's hospital file. Patients were asked about the foot problem related to diabetes. As numbness mostly represents the neuropathy, so they were asked about the feeling of numbness in their feet and when the numbness mostly feels in daily life so it determines the grading of disease severity. They were also asked about the sensation of burning in their feet. Some psychogenic conditions have also been recorded like how people treat them due to their feet problem, to what extent they are dependent on others, the rate of depression in their life due to the foot problem, etc. To determine the medical care patients were asked about their treatments that have been suggested by their physician or the other preventions they did for health care and to control diabetes.

\section{FAMILY HISTORY:}

A positive family history of diabetes was considered if the patient had a parent or a sibling who had it. Hypertension: patients were considered to have hypertension if their systolic blood pressure was greater than $130 \mathrm{mmHg}$ and the diastolic blood pressure was greater than $85 \mathrm{mmHg}$. Smoking: a smoker was defined as a person who smoked at least more than 3 cigarettes per day for the preceding three months or more or had tobacco in any form.

\section{BLOOD PRESSURE:}

A sphygmomanometer was used to compute the blood pressure. Prior taking readings, the patient was asked to sit back comfortably and to relax. 5 minutes later the deflated cuff was wrapped around the upper arm and the valve on the rubber bulb was closed. The stethoscope placed over the pulse, under cuff. Then the cuff was pumped up by squeezing the bulb, and as the pressure was released the korotkoffs sounds were heard through the pieces of air of the stethoscope. Blood pressure (systolic/diastolic) was measured in terms of millimeters of mercury $\mathrm{mm} \mathrm{Hg}$.

BMI: In order to evaluate if the patients were overweight or not, the body mass index was computed for every individual. After measuring the weight in kilograms and height in meters, the BMI was calculated by the following formula.

$$
\mathrm{BMI}=\mathrm{kg} / \mathrm{m} 2
$$




\section{RESULTS:}

There were total 55 patients of Diabetic peripheral neuropathy patients participated in this study. Table I shows the comparison of male and female various clinical parameters including: age, BMI, blood pressure and diabetic duration. The mean age was $58.8 \pm 9.6$, females $50.7 \pm 9.1$ were significantly younger than male counter parts $55.1 \pm 9.4$ (Table I).

Table I: The Demographics and clinical variables related to diabetic peripheral neuropathy

\begin{tabular}{|c|c|c|c|c|}
\hline Characteristics & $\begin{array}{c}\text { Total sample } \\
(\mathbf{n}=\mathbf{5 0})\end{array}$ & $\begin{array}{c}\text { DPN Male } \\
\text { subjects }(n=33)\end{array}$ & $\begin{array}{c}\text { DPN female } \\
\text { subjects }(n=17)\end{array}$ & $p$-value \\
\hline & Mean \pm SD & Mean \pm SD & Mean \pm SD & $\begin{array}{l}\text { Pearson chi } \\
\text { square test }\end{array}$ \\
\hline Age (years) & $58.8 \pm 9.6$ & $55.1 \pm 9.4$ & $50.7 \pm 9.1$ & 0.032 \\
\hline $\begin{array}{l}\text { Diabetes duration } \\
\text { (years) }\end{array}$ & $8.0 \pm 1.8$ & $7.8 \pm 1.4$ & $6.6 \pm 1.3$ & 0.05 \\
\hline Waist/hip ratio & $0.93 \pm 0.04$ & $0.9321 \pm 0.0467$ & $0.9324 \pm 0.0612$ & 0.436 \\
\hline BMI $\left(\mathrm{kg} / \mathrm{m}^{2}\right)$ & $25.67 \pm 2.35$ & $24.56 \pm 3.20$ & $25.34 \pm 2.36$ & 0.491 \\
\hline Hypertension & $142 \pm 1.93$ & $140 \pm 1.3$ & $124 \pm 1.67$ & 0.187 \\
\hline
\end{tabular}

In this cross-sectional study, table II outlines the prevalence of various sign and symptoms that are associated with diabetic neuropathy. Numbness and excessive feeling of hot and cold in lower extremities is the most prevalent symptom reported in both genders. $17 \%$ feels burning sensation in feet at night and, $16 \%$ don't feel burning sensation. $11 \%$ feels burning sensation in feet at night. $19 \%$ feels excessive heat or cold sensations while $14 \%$ did not feel the same. $10 \%$ feels excessive heat or cold sensation $7 \%$ did not feel the same. $18 \%$ had numbness in their feet while $13 \%$ doesn't feel. $8 \%$ had numbness in their feet $7 \%$ doesn't feel.

Table II: Analysis of various sign and symptoms related to diabetic peripheral neuropathy

\begin{tabular}{|l|c|c|c|}
\hline \multicolumn{1}{|c}{ Signs } & \multicolumn{1}{c}{$\begin{array}{c}\text { DPN Male } \\
\text { Subjects (n=33) }\end{array}$} & $11 \%$ & 0.933 \\
\hline $\begin{array}{l}\text { Feeling of burning in } \\
\text { legs \& feet }\end{array}$ & $17 \%$ & $12 \%$ & 0.933 \\
\hline $\begin{array}{l}\text { Feeling of excessive } \\
\text { heat or cold in hands } \\
\text { and feet }\end{array}$ & $19 \%$ & $10 \%$ & 0.746 \\
\hline Numbness in feet & $18 \%$ & $6 \%$ & 0.052 \\
\hline $\begin{array}{l}\text { Inability to feel objects } \\
\text { with feet }\end{array}$ & $4 \%$ & $5 \%$ & 0.693 \\
\hline $\begin{array}{l}\text { Inability to feel } \\
\text { difference b/w hot and } \\
\text { cold }\end{array}$ & $8 \%$ & $10 \%$ & 0.029 \\
\hline $\begin{array}{l}\text { Instability when } \\
\text { walking }\end{array}$ & $9 \%$ & $5 \%$ & 0.52 \\
\hline Weakness in hands & $7 \%$ & $9 \%$ & 0.118 \\
\hline $\begin{array}{l}\text { Physically or } \\
\text { emotionally dependent } \\
\text { on others }\end{array}$ & $10 \%$ & & \\
\hline
\end{tabular}


Biosight 2021; 02(01): 24-30

\begin{tabular}{|l|c|c|c|}
\hline $\begin{array}{l}\text { Depression due to foot } \\
\text { problem }\end{array}$ & $15 \%$ & $9 \%$ & 0.616 \\
\hline Rate of quality of life & $15 \%$ & $9 \%$ & 0.873 \\
\hline $\begin{array}{l}\text { Foot problem makes } \\
\text { self-constrained }\end{array}$ & $11 \%$ & $6 \%$ & 0.89 \\
\hline $\begin{array}{l}\text { Foot problem turns life } \\
\text { into struggle }\end{array}$ & $11 \%$ & $7 \%$ & 0.584 \\
\hline $\begin{array}{l}\text { Effects on Self } \\
\text { confidence }\end{array}$ & $12 \%$ & $7 \%$ & 0.74 \\
\hline $\begin{array}{l}\text { Foot problem makes } \\
\text { them feel older }\end{array}$ & $12 \%$ & $8 \%$ & 0.465 \\
\hline
\end{tabular}

$4 \%$ male were unable to feel objects with their feet because of loss of sensations while $29 \%$ male were able to do such things. $6 \%$ female were unable to feel objects with their feet because of loss of sensations while $11 \%$ female were able to do. $8 \%$ male were unable to differentiate the feel of hot and cold while $25 \%$ male were not. $5 \%$ female were unable to differentiate between hot and cold while $12 \%$ female were not. $9 \%$ male feels instability when walking with their disease while $24 \%$ male did not feel such difficulties. $10 \%$ female feels instability when walking with their disease while $7 \%$ female did not feel such difficulties. $7 \%$ male feels weakness in hands while $26 \%$ male did not feel weakness in hands. 5\% female feels weakness in hands while $12 \%$ female did not feel weakness in hands. $10 \%$ male were physically as well as emotionally dependent on others while $23 \%$ male were not. $9 \%$ female were physically as well as emotionally dependent on others while $8 \%$ female were not. $15 \%$ male were suffering from depression while $18 \%$ male were not. $9 \%$ female were suffering from depression while $8 \%$ female were not. $15 \%$ male rate their quality of life as good, $13 \%$ male rate as normal and $5 \%$ male rate their life quality as bad. $9 \%$ female rate their quality of life as good, and $6 \%$ female rate as normal, $2 \%$ female rate their life quality as bad. $11 \%$ were self-constrained and $22 \%$ male were not. $6 \%$ female were selfconstrained, while $11 \%$ female were not. $11 \%$ have struggling life because of neuropathy, $22 \%$ male and $10 \%$ female were not struggling. $7 \%$ female have struggling life because of neuropathy. $12 \%$ loses their self confidence in society because of the disease complications, while $21 \%$ did not lose their self-confidence. $7 \%$ female loses their self confidence in society because of the disease complications. $10 \%$ female did not lose their self-confidence. $12 \%$ feels older than their age because of the disease while $21 \%$ don't feel the same. $8 \%$ female feels older than their age because of the disease. 14\% take medications by doctor's suggestion, $3 \%$ follows diet plan, $1 \%$ male and $0 \%$ female take insulin, $5 \%$ take mediation as well as diet suggestions.

\section{DISCUSSION:}

Peripheral neuropathy is a tremendously widespread condition, specifically in old age. Furthermore, a remarkable percentage of patients with peripheral neuropathy have no visible underlying cause of this disease. Therefore, a better perception of this disease root is needed to mention the progress of new disease modifying treatments and health care [3].

Diabetic patients can be at very high risk for peripheral neuropathy and severe foot ulcers which leads to amputation. The main motive of the study was to evaluate the probability of danger factors of peripheral neuropathy in the diabetic patients. According to my study lack of awareness in patients heightens the risk of disease and neuropathies. Lack of awareness keeps a wide part of the population with the elevated blood sugar level as the majority of the population with risks of diabetes does not take regular checkups. Only about $10 \%$ of the people who are at the risk of developing diabetes know about their condition, which makes it difficult to take proactive measures. Social media usage is elevating rapidly in health care and diabetes as well. However, patients, health care personnel, and patient organizations discuss diabetes on social 
media in many different ways. Social media have much potential and influence for better communication if patients and others as well know about, acknowledge, and accept one another's views regarding health care programs [11].

According to the current study out of 50 patient populations, $32 \%$ male and $18 \%$ female have past family history for the diabetes [4]. Mostly the patients with painful diabetic neuropathy feel pain, numbness, tingling or burning in legs or feet and this pain may mainly feel at night. As I found in my research $26 \%$ of the patients feel numbness in their feet and $28 \%$ population out of $50 \%$ feels burning sensation in their feet mainly at night which makes very hard for them to fall asleep. As I observed in patients during my survey there is a loss of sensation in the lower extremities when blood sugar level increases which causes burning, tingling and prickling sensation in feet.

Foot problems due to the diabetes, diminished the quality of life. $26 \%$ of the patients, according to my survey out of total 50 patients have poor life experiences and bad quality of life because of these foot problems. $22 \%$ of the patients have poor experiences in their relationship and daily activities of life. And 19\% of them were physically/emotionally dependent on others because of their foot problem.

According to the current research, out of 50 patients, $20 \%$ patients feels old because of their foot problem, self-confidence of $19 \%$ patients is affected, $18 \%$ patients were facing struggles, the foot pain makes $17 \%$ people self-constrained, and $24 \%$ becomes very depressed due to increased pain and foot injuries.

\section{CONCLUSION}

It has been observed that most of the patients due to lack of awareness are suspected to the elevated blood sugar level which leads to neuropathy. Due to the diabetic peripheral neuropathy majority of the patients facing foot problems, foot ulcers and ultimately managed with amputations. Lack of awareness, lack of health management, obesity, blood pressure changes, less care plays a key role in increasing the chances of diabetic neuropathy. Genetics also plays a major role in diabetes.

\section{ETHICS APPROVAL AND CONSENT TO PARTICIPATE}

Not applicable.

HUMAN AND ANIMAL RIGHTS

Not applicable.

\section{CONSENT FOR PUBLICATION}

Not applicable.

\section{AVAILABILITY OF DATA AND MATERIALS}

None.

\section{FUNDING}

None.

\section{CONFLICT OF INTEREST}

The authors declare no conflict of interest, financial or otherwise.

\section{ACKNOWLEDGEMENTS}


The authors acknowledge academic and non-academic staff of Department of Physiology, University of Karachi, for their valued cooperation during the research conduct for completion of the study.

\section{REFERENCES:}

1. Boulton A. Management of Diabetic Peripheral Neuropathy. Clinical Diabetes. 2005; 23(1):9-15.

2. Callaghan B, Gao L, Li Y, Zhou X, Reynolds E, Banerjee M et al. Diabetes and obesity are the main metabolic drivers of peripheral neuropathy. Annals of Clinical and Translational Neurology. 2018; 5(4):397-405.

3. Davies M, Brophy S, Williams R, Taylor A. The Prevalence, Severity, and Impact of Painful Diabetic Peripheral Neuropathy in Type 2 Diabetes. Diabetes Care. 2006; 29(7):1518-1522.

4. Årsand E, Bradway M, Gabarron E. What Are Diabetes Patients Versus Health Care Personnel Discussing on Social Media?. Journal of Diabetes Science and Technology. 2019; 13(2):198-205.

5. Faselis C, Katsimardou A, Imprialos K, Deligkaris $P$, Kallistratos M, Dimitriadis K. Microvascular Complications of Type 2 Diabetes Mellitus. Current Vascular Pharmacology. 2020; 18(2):117-124.

6. Ishibashi F, Kosaka A, Tavakoli M. The Impact of Glycemic Control on Retinal Photoreceptor Layers and Retinal Pigment Epithelium in Patients with Type 2 Diabetes without Diabetic Retinopathy: A Follow-Up Study. Frontiers in Endocrinology. 2021; 12.

7. Majumder A, Chatterjee S, Maji D. Peripheral neuropathy in diabetes. J Indian Med Assoc. 2013 Jun; 111(6):382, 384-6. PMID: 24761495.

8. McNeely M, Boyko E, Ahroni J, Stensel V, Reiber G, Smith D et al. The Independent Contributions of Diabetic Neuropathy and Yasculopatny in Foot Ulceration: How great are the risks. Diabetes Care. 1995; 18(2):216-219.

9. Ponirakis G, Petropoulos I, Alam U, Ferdousi M, Asghar O, Marshall A et al. Hypertension Contributes to Neuropathy in Patients With Type 1 Diabetes. American Journal of Hypertension. 2019; 32(8):796-803.

10. O'Brien S, Schwedler M, Kerstein M. PERIPHERAL NEUROPATHIES IN DIABETES. Surgical Clinics of North America. 1998; 78(3):393-408.

11. Tesfaye S, Boulton A, Dyck P, Freeman R, Horowitz M, Kempler $\mathrm{P}$ et al. Diabetic Neuropathies: Update on Definitions, Diagnostic Criteria, Estimation of Severity, and Treatments. Diabetes Care. 2010; 33(10):2285-2293.

12. Thomas P. Classification, Differential Diagnosis, and Staging of Diabetic Peripheral Neuropathy. Diabetes. 1997; 46(Supplement_2):S54-S57.

13. Vinik A, Casellini C, Parson H, Colberg S, Nevoret M. Cardiac Autonomic Neuropathy in Diabetes: A Predictor of Cardiometabolic Events. Frontiers in Neuroscience. 2018; 12:591. 